\title{
Evolution of Transient Saturated Zones and Stability Analysis of High Liquid Limit Red Clay Slope under Rainfall Conditions
}

\author{
Xiang Qiu \\ School of Civil Engineering, Changsha University of Science \& Technology \\ No.960, Section 2, Wanjiali South Road, Changsha, China \\ qiuxiang@csust.edu.cn
}

\section{Extended Abstract}

High liquid limit red clay (HLLRC) is widely distributed in southern China. Under the influence of long-term humid and hot environment, the shallow landslide of HLLRC cut slopes frequently occurs and it is difficult to control, which seriously affects traffic safety and smoothness ${ }^{[1]}$. Studies have shown that under rainfall conditions, some temporally and spatially evolving transient saturated zones will form inside the slope, which will cause the continuous degradation of the rock and soil mechanical properties of the slope in this zone, and eventually cause the slope to instability ${ }^{[2]}$. Therefore, exploring the evolution of the transient saturation zone of HLLRC slopes under rainfall conditions can provide an effective theoretical basis for HLLRC slopes stability analysis.

To explore the evolution characteristics of the transient saturated zone of HLLRC cut slopes under rainfall conditions, this paper carried out numerical simulation calculations of rainfall infiltration on cut slopes under different conditions based on saturated unsaturated seepage theory ${ }^{[3]}$. The formation conditions of the transient saturation zone under different rainfall conditions and the influence of factors such as rainfall intensity, soil saturated permeability coefficient, slope gradient on the evolution characteristics of the transient saturation zone were analyzed. Starting from the relationship between the potential sliding surface of the HLLRC cut slope and the position of the transient saturated zone, a slope stability coefficient calculation formula that can consider both the transient water pressure and the soil strength in the unsaturated zone was derived. A slope stability analysis program that can automatically search for the location of the sliding surface is developed, and the program is used to study the safety factor and instability mode evolution law of a HLLRC cut slope.

The results show that the rainfall intensity greater than or equal to the soil saturated permeability coefficient and soil and the continuous penetration of rainwater into the pores of the saturated soil are two important conditions for the formation of the transient saturated zone. In the early stage of rainfall, the shallow soil of the slope reaches saturation first, and gradually forms a transient saturation zone. As the rainfall continues, the transient saturation zone expands towards the foot of the slope. After the rainfall ceases, the water pressure and volumetric water content of the soil pores above the groundwater level will continue to decrease, and the groundwater level will continue to rise, eventually converging with the transient saturation zone. In addition, under different conditions, the area of the transient saturation zone first gradually increased, then increased rapidly, then stabilized, and finally decreased gradually with the increase of rainfall duration. At the same time, a slope stability calculation method based on the improved Swedish arc method is proposed, which can effectively solve the problem of HLLRC cut slope stability analysis. The threshold value for the transformation of the deep instability and shallow instability modes of the slope was obtained, and the threshold can be defined by the depth of the rainfall infiltration zone. When the depth of the rainfall infiltration zone is less than the threshold, the safety factor of the slope decreases rapidly, the maximum depth of the sliding surface decreases rapidly, and the slope instability mode is manifested as deep-seated overall failure, and vice versa anyway.

\section{References}

[1] L. Zeng, F. Li and Q. F. Gao, et al, "Insight into the fracturing of silty mudstone in cyclic hydrothermal environments based on computed tomography," Transp Geotech., vol. 26, no. 4, pp. 100432, 2021.

[2] L. Zeng, H. Bian and Z. Shi, et al, "Forming condition of transient saturated zone and its distribution in residual slope under rainfall conditions," J Cent South Univ vol. 24, no. 8, pp. 1866-1880, 2017.

[3] L. A. Richards, "Capillary conduction of liquids through porousmedium," Phy, vol. 1, no. 5, pp. 318-333, 1931. 